Portland State University

PDXScholar

12-8-1976

\title{
Approaches to Composition in Selected Directing Texts: A Structural Analysis and Assessment
}

Kathryn C. Dodele

Portland State University

Follow this and additional works at: https://pdxscholar.library.pdx.edu/open_access_etds

Part of the Other Theatre and Performance Studies Commons, and the Performance Studies

Commons

Let us know how access to this document benefits you.

\section{Recommended Citation}

Dodele, Kathryn C., "Approaches to Composition in Selected Directing Texts: A Structural Analysis and Assessment" (1976). Dissertations and Theses. Paper 2470.

https://doi.org/10.15760/etd.2467

This Thesis is brought to you for free and open access. It has been accepted for inclusion in Dissertations and Theses by an authorized administrator of PDXScholar. Please contact us if we can make this document more accessible: pdxscholar@pdx.edu. 
AN ABSTRACT OF THE THESIS OF Kathryn Dodele for the Master of Arts in Theatre presented December 8, 1976.

Titles spproaches to Composition in Selected Directing Texts: A Structural Analysis and Assessment.

\section{APPROVED BY MEMBERS OF THE THESIS COMMITTEE;}

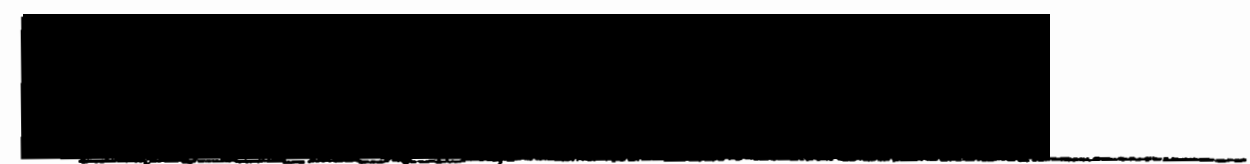

Whliam Tate, Chairman

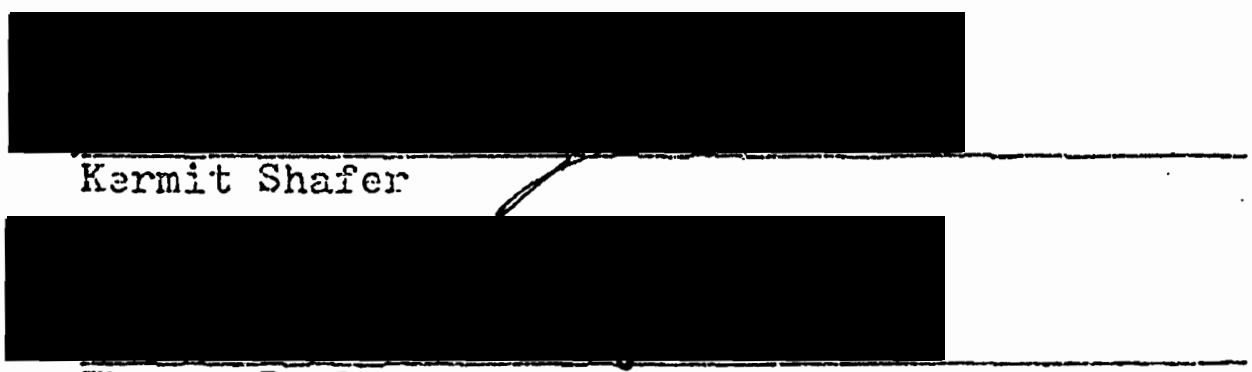

Thomas Bue1

Directing texis are inadequate in their various approsches to teaching the concepts of stage-icomposition. The goal of this thesis was to show that, for an approach to stage composition to be judged adequate, it must systematically provide the student of direoting with a firm grounding in design and compositional principles as they relate to the total stage picture.

Nineteen iexts were studied and tireir presentations of compositional principles were analyzed. Eight texts are included in as in-depth structural anajysis. The texts 
analyzed are Fundamentals of Play Directing by Alexander Dean, The Art of Play Production by John Dolman, Play Direction by John Deitrich, Principles of Theatre Art by $H . D$. Albright, W. P. Halstead, and Lee Mitchell, Directing Methods by Albert and Bertha Johnson, Play Directing by Francis Hodge, Creating. Theatre by August Staub and Creative Play Directing by Robert Cohen and John Harrop.

The analysis of these texts includes a detailed comparison of terminology and approaches to the presentation of compositional principles. Of the nineteen texts included in this investigation, only one, Creating Theatre by August Staub, presented a systematic approach to design f'undamentals and compositional. principles as they relate to the director's function.

Also included in this thesis are the writer's criteria for judging the adequacy of approaches to composition in any directing text.

The conclusion reached by the writer is that the authors of texts on directing, as weil as the schools that offer programs in theatre arts, need to emphasize design fundamentals as an essential element in any theatre student's training. 
APPROACHES TO COMPOSITION IN SELECTED DIRECTING TEXTS;

A STRUCTURAL ANALYSIS AND ASSESSMENT

by

KATHRYN C. DODELE

A thesis submitted in partial fulfillment of the requirements for the degree of

MASTER OF ARTS

in

THEATRE

Portland State University

1976 
TO THE OFFICE OF GRADUATE STUDIES AND RESEARCH:

The members of the Committee approve the thesis of Kathryn Dodele presented December 8, 1976.

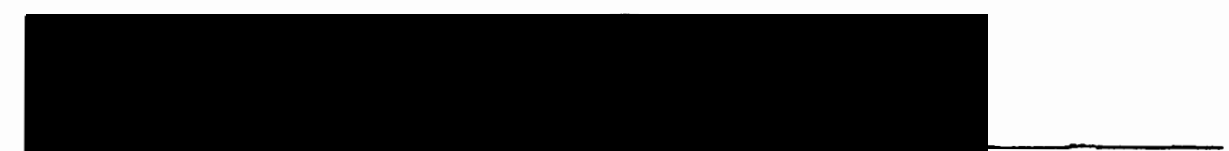

William Tate, Chairman

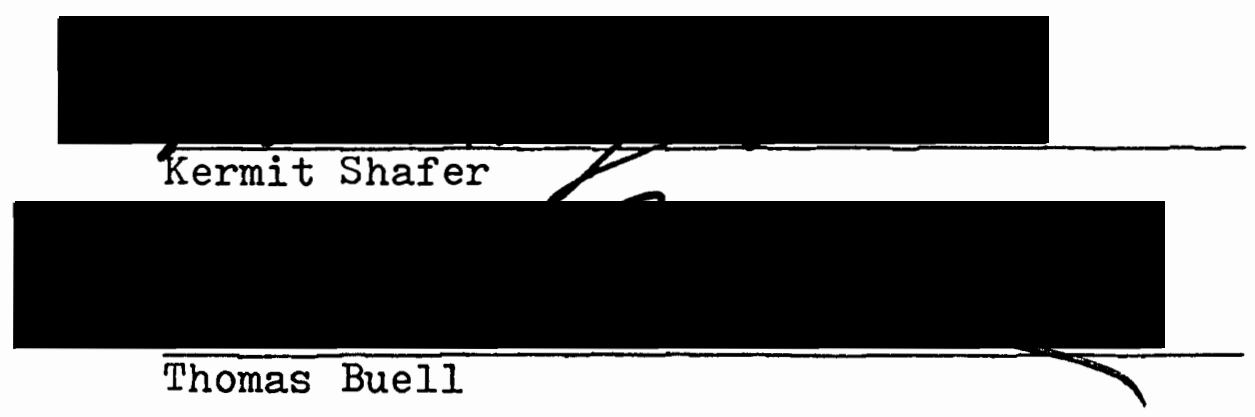

APPROVED:

Asher Wilson, Head, Department of Theatre

Stanley E. Rauch

Dean of Graduate Studies and Research 
TABLE OF CONTENTS

PAGE

CHAPTER

I INTRODUCTION . . . . . . . . . . 1

II PRESENTATION OF THE PROBLEM • • • • • 6

III ANALYSIS OF SELECTED TEXTS . • • . . . . 9

IV CRITERIA FOR JUDGING . . . . . . . 32

Adequacy of Approaches to Composition in Directing Texts ....... 32

$\mathrm{V}$ CONCLUSION . . . . . . . . 36

ANNOTATED BIBLIOGRAPHY . . . . . . . . 40

APPENDIX . . . . . . . . . . . . . 45 
CHAPTER I

\title{
INTRODUCTION
}

\begin{abstract}
The theatre of today embraces so many forms of activity that an exact definition of the director's problems and responsibilities is hardly possible. . . Never in history have there been so many kinds of theatre, good and bad; never in history have theatre goers been so uncertain in their minds as to what constitutes good theatre. ... Never, in other words, was the theatre as heterogeneous as it is today.

The Art of Play Production, 3rd Ed. John Dolman, Jr. and Richard Knaub
\end{abstract}

As the nature of the theatre becomes more complex, the role of the director becomes more challenging. There are no constants in his life. Stage structures change. Acting methods are in a constant state of flux. His scripts vary from Elizabethan tragedy to environmental "happenings." Yet, with all these inconsistencies in the modern theatre, perhaps the best definition of the director is still the one written by Sheldon Cheney in 1917 .

$$
\begin{aligned}
& \text { The } \cdot \text { director } \cdot \text { is artist enough to } \\
& \text { harmonize the provisional or incomplete arts } \\
& \text { of the playwright, the actor, the scene de- } \\
& \text { signer, and at the same time develop by a } \\
& \text { creative method of production, an inner rhythm, } \\
& \text { a complete theatre unity. } 1
\end{aligned}
$$

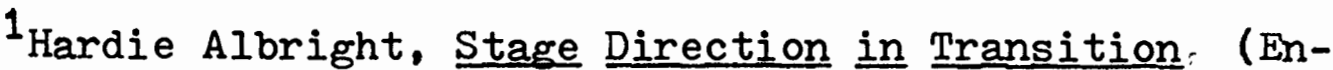
cino and Belmont, California: Dickerson Publishing Co., Inc., 1972), p. 3 . 
Various authors of directing texts use different terminology when defining this "creative method of production." The two major aspects in all the methods suggested are analysis of the text and communication of the director's interpretation to the actors, designers and the audience. It is with the second aspect that this thesis is concerned. More specifically, it is concerned with visual means of communication available to the director through the art of composition in staging.

After extensive research a list of the major directing texts published in the last thirty-five years has been compiled. A survey of these texts is available in the annotated bibliography of this thesis. From this list, the following texts were chosen for a detailed analysis: Fundamentals of Play Directing by Alexander Dean, published in 1941, The Art of Play Production by John Dolman, (1946), Play Direction by John Deitrich, (1953), Principles of Theatre Art by H. D. Albright, W. P. Halstead and Lee Mitchell, (1955), Directing Methods by Albert and Bertha Johnson, (1970), Play Directing by Francis Hodge, (1971), Creating Theatre by August Staub: (1973), and Creative Play Directing by Robert Cohen and John Harrop, (1974).

It is the purpose of this thesis to examine, in depth, the discussions of composition found in these eight texts, to analyze their structure and content, and finally, present criteria for assessing the adequacy of the composition sec- 
tion of any directing text. These texts were chosen for detailed discussion because they presented unique approaches to composition in staging or suggested notable additions to established approaches. One text was chosen because it presents an identifiably confusing discussion of composition. Philosophical approaches and organizational patterns of the texts will also be examined and, in some cases, be compared with preceding publications.

Before beginning this analysis, it is necessary to define a few terms. This is not an easy thing to do, since definitions are one of the most confusing aspects of directing texts. Composition is a key word. Four of the eight selected texts do not define it. One defines it as "the structure, form or design of the group. It is not, however, the meaning of the picture." 2 Another defines composition as "the artistic and meaningful arrangement of character on a stage . . meaning must be the first consideration." 3 The first problem is evident. Does composition include meaning? For the purposes of this thesis, meaning will not be included in the definition of composition. The meaning of the stage, picture can be referred to by the term "picturization," defined in one text as "the visual interpretation

${ }^{2}$ Alexander Dean, Fundamentals of Play Directing (New York: Farrar and Rinehart, Inc., 1941), p. 107.

3 John Deitrich, Play Direction (New York : PrenticeHall, 1953), p. 92 . 
of each moment in the play." 4 So it would seem that composition would be "the structure, form, or design of the group" and picturization, "the visual interpretation (or meaning) of each moment of the play." It is unfortunately not that simple. Another author states, "Visual design--or picturization, as it is often called in the theatre--is the emotional and intellectual meaning of the composition." 5 Dean included the term "design" in his definition of composition. Staub says "design" means picturization. If we remove design from the first definition, we conclude that composition is "the structure and form of the group." It is with this structure and form that this paper is primarily concerned. However, design, or "picturization," will be discussed in regard to certain selections because, although they can be defined separately, design and composition should never be separated for their application in staging. Since both composition and picturization apply to the static stage picture, stage movement will not be discussed. Just as a director's methods can be divided into analys is and communication, the dramatic process can be divided into two units, "composition--movement--composition--movement." 6 Although all aspects of the theatre are integrated and de-

4 Dean, p. 172 .

5 August Staub, Creating Theatre (New York, Evanston, San Francisco, Iondon, Harper and Row, Publishers, 1973), p. 138 .

$$
{ }^{6} \text { Deitrich, p. } 91 .
$$


pendent upon each other, discussion of movement is no more relevant here than a discussion of script analysis or sound effects. 
In the theatre, the problem of design is especially complex because of the composite nature of the art and the large number of elements that have to be considered and put in order. . .

The Art of Play Production John Dolman

Not only is artistic composition in staging difficult to master because of its inherent complications, but the lack of adequate approaches to composition in directing texts confuses the student director and makes the problem seem insurmountable. Not only is there disagreement as to the nature of composition, there is doubt as to its value to the student director. Some authors believe that composition should not be dealt with formally, some believe the study of composition is too advanced for the student director, and others believe it is an essential tool for the director to master.

The differences noted above suggest an order for examining the chosen, texxts. Dean (1941) and Dolman (1946) are fundamentalists. They believe composition and design are essential tools for the director to master and present detailed discussions of the concepts, but because they are writing entirely about composition as it relates to the 
proscenium stage, their explanations do not systematically relate compositional and design principles to the total stage picture. The total stage picture includes sets, properties, actor configuration and lighting, and must be considered in the three dimensional context of open staging as well as the two dimensional picture frame of the proscenium stage. Deitrich (1953) and Albright, Halstead and Mitchell (1955) are in the Dean-Dolman tradition. They seem to recognize the value of the material presented by Dean and Dalman, though they attempt to refine and clarify the ideas. Their frame of reference is still proscenium staging. Directing Methods, by Albert and Bertha Johnson, is one of several texts that attempts to popularize the art of directing by over-simplification of the concepts. The Johnsons include most of the ideas mentioned in earlier texts but their simplifications confuse rather than clarify. Along with the popularizers, there have also appeared the innovators. These authors reject the need for formal training in design and composition. They interpret the principles of design as too complex or too prescriptive. The two innovative books discussed at length in this thesis are Play Directing by Francis Hodge, published in 1971, and Creative Play Direction by Robert Cohen and John Harrop, published in 1974. Hodge believes the principles of design are too complex for the beginning director and unnecessary in his method of teaching directing. Cohen and Harrop fear 
the restrictive capabilities of the rules of composition and do not discuss them. The final text discussed at length will be Creating Theatre by August Staub. Staub's orientation is neo-fundamentalist. He relates his work to both proscenium and open staging, but he includes fundamental instruction in the principles of visual art. He integrates old rules and new concepts to show that fundamentals are still essential in contemporary theatre.

Before beginning the analysis of the eight selected texts, another major point must be clarified. A distinction must be made between the "elements of composition" and the "goals of composition." Many authors of directing texts fail to distinguish between them. August Staub, in Creating Theatre, is the only writer of those examined who elaborates the difference. After much analysis and comparison, it is my intention to adopt Mr. Staub's scheme for this paper. He first discusses the elements of composition, then the goals of composition. He relates them to each other and to design and picturization. The elements of composition as this writer will employ them are line, form, mass, space, color and texture.? The goals are unity, balance, emphasis, variety and rhythm. 8

\footnotetext{
7Staub, p. 95.

8 Ibid., p. 110.
} 
Fundamentals of Play Directing by Alexander Dean "evolved initially as an expansion of the first third of his Syllabus of A Course in Play Directing and included the material covered in the first year class in directing as he gave it at the department of Drama, Yale University. . . There:was still work to be done on Professor Dean's manuscripts at the time of his death [in 1939]."9 Fundamentals of Play Directing has a seemingly complete, detailed and well illustrated section dealing with composition in staging. It has the earliest date of publication of the texts selected for this study. Dean's influence on subsequent authors will be easily recognized.

In his sixty-four page chapter entitled "Composition," Dean discusses emphasis for forty-one pages. The major section of this discussion are "Methods of Obtaining Emphasis," "Variety in Emphasis," "Other Methods of Obtaining Emphasis," "Kinds of Emphasis," and "Special Problems in Emphasis." The remaining twenty-three pages include sections on "Stability," "Sequence," "Balance," and "Effect of Composition on Audience Emotions," which contains the sub-sections,

${ }^{9}$ Lawrence Carra, Preface, Fundamentals of Play Directing, ( $3 r d$ ed., New York: Holt, Rinehart, and Winston, 1974), pp. vii-viii. 
"Line," "Mass," and "Form."

The quality and complexity of Dean's work, while being excellent in themselves, are responsible, in large part, for the ineffectiveness of subsequent texts on the use of composition in staging. An analogy might be drawn between Alexander Dean and Aristotle. Both were right about so many things that scholars could not see their errors or shortcomings. In the case of Dean and directing, authors of directing texts have re-arranged, repeated and/or rejected his ideas. Among other writers, Deitrich, ${ }^{10}$ Seivers $^{11}$ and Gregory ${ }^{12}$ repeat his section on emphasis almost word for word. It is interesting to note, however, that while Dean's theories, particularly those dealing with emphasis, are widely used, the terminology used by most writers is more closely related to John Dolman.

John Dolman's text, The Art of Play Production, was first published in 1946. Dolman places heavy emphasis on aesthetic values. He states that "it is inconceivable--and unnecessary--that the stage director should be so expert in all the arts as to compete with specialists, but it would seem particularly essential that he know the underlying

10Deitrich, Play Direction, pp. 103-113.

11W. David. Seivers, Directing for the Theatre (Dubuque, Iowa William C. Brown, 1965), pp. 105-116.

${ }^{12}$ W. A. Gregory, The Director: A Guide to Modern Theatre Practices (New York: Funk and Wagnalls, 1968), pp. 
principles of good design common to all of them."13 Most of Dolman's discussion of composition is included in his chapters entitled, "Play Production as Design," and "Control of Attention." Chapter four, "Play Production as Design," discusses the goals of design. They are unity, emphasis, rhythm, balance, proportion, harmony and grace. The discussion of these goals is prefaced with discussions of the origins of design, the utilitarian basis of design and fidelity to materials. The explanation of the goals themselves is limited to relatively short sub-sections, which define and explain the goals, but fail to delineate applications. For example, when discussing rhythm, Dolman states,

Rhythm is the periodicity or pulsation or the more or less regular recurrance of emphasis. If rhythm is made too obvious, it may distract attention from the main thought to be conveyed, and the technique of the art may become unpleasantly mechanical. On the other hand, if there is not enough rhythm, or if the rhythms are confused, our motor responses are baffled and we experience a sense of restless futility and dissatisfaction. 14

Although Dolman asserts that, "no stage director can possibly know too much of the principles of design, or have his tastes and sensibilities too highly trained,"15 The Art of Play Production has a totally unstructured approach to the application of compositional principles. Dolman pre-

\footnotetext{
13 Dolman, p. 58 .

${ }^{14}$ Ibid. . p. 71 .

$15_{\text {Ibid.. p. } 83 .}$
} 
sents a convincing theoretical argument, but fails to follow through with a method of practical application.

John Deitrich combines and refines the ideas of Dean and Dolman and contributes a significant amount of additional material. His text, Play Direction (1953) has a twentyseven page chapter on composition. Deitrich, however, includes the concept of picturization within his definition of composition, thus covering in twenty-seven pages the material Dean covers in eighty-two. It is important to note that Dean's text includes many photographs while Deitrich has no photographs in his entire text. This very fact weakens Deitrich's presentation, because it is extremely difficult to discuss visual principles without visual reinforcement.

The first section of Deitrich's chapter, "Motivational Aspects of Composition," is actually a discussion of picturization. Deitrich then includes a section on the "Technical Aspects of Composition," such as sight lines, the fourth wall, the framed picture and nomenclature of the playing area. He includes sections dealing with emphasis which are entitled "Control of Attention," "Geometric Arrangements," and "The Relative Strength of Compositional Factors." These sections account for thirteen of the twentyseven pages of the chapter. Deitrich, like Dean, seems to believe that emphasis is the most important factor in composition. Deitrich also parallels Dean in his sub-sections 
dealing with emphasis. Both include discussions of emphasis through body position, playing area, level, space, focus, and contrast. The remaining sections of the chapter on composition offer ideas and vocabulary similar to that of Dolman. In his section entitled "Pictorial Aspects of Composition," Deitrich discusses unity, variety, coherence, balance, rhythm, grace, harmony and contrast.

Principles of Theatre Art, by H. D. Albright, W. P. Halstead and Lee Mitchell, published in 1955, is a highly informative book. The authors define variety, style, atmosphere, picturization and progression, thus adding two more terms--atmosphere and progression--to the developing list of goals of composition. Their approach to the other goals of composition are unique to the books studied. They state, "Balance, proportion, unity and rhythm can be employed creatively, but usually they are used as standards for evaluating the whole production, and the director looks for violations, rather than deliberately patterning with these elements in mind."16 With this statement, they introduce the negative approach to composition. The strength and impact of Principles of Theatre Art is found in the concise, uncomplicated statements concerning the principles under consideration. Statements such as, "The performance of a play, being a temporal art as well as a spatial one, allows no

${ }^{16}$ H. D. Albright, W. P. Halstead and Lee Mitchell, Principles of Theatre Art (Boston: Houghton Mifflin Co., 1955), p. 395 . 
opportunity for return, and the director must make each phase of the temporal pattern, such as speech and action-comprehensible at the brief instant of its occurance."17 The summary of the goals of composition is one of the best available in the texts surveyed.

Attention of the audience is secured and guided by emphasis and subordination. Variety assists in holding this attention, and in addition, provides an aesthetic pleasure in itself. Style and atmosphere can assist organization by increasing the consistency of impression or by providing meaningful variety. Picturization clarifies the meaning. Balance, proportion and unity are compositional patterns which give an over-all effect of symmetry, equilibrium and plan. Balance is concerned with equilibrium on the two sides of the axis or climax; proportion with the appropriate relation of details one with another and between the form and content; and unity with the appropriateness of the selection of the particulars.18

These statements help the student of directing see the interrelationships of the principles of composition. While the section on scene design contains information on the elements of design, Albright, Halstead and Mitchell still fail to provide, systematically, a firm grounding in design and compositional principles as related to the total stage picture.

The first half of chapter seven in Albert and Bertha Johnson's text, Directing Methods (1970), deals with stage composition. The second half deals with the dynamics of

17 Albright, Halstead and Mitchell, p. 395.

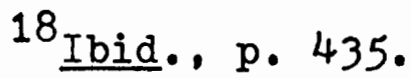


movement and will not be examined. The Johnsons include an interesting discussion of the uses of various stage areas. For example, "Down right, being a strong area, is a good place for a man-to-man conversation. . . It is an area of intimacy, in comparison to the down left area... which is a good area for the underdog or for the villain to cry quits."19 They include similar suggestions for up right and up left. It is worth noting that, after this fairly simplistic discussion of the effect and use of various stage areas, the Johnsons warn that the director, learning a few basic theories of composition and movement, "may run the risk of letting theory replace intuitive judgement, assuming he has intuitive judgement, and in any case, he is pretty likely, from time to time, to get caught with his technique showing. "20 If the beginning director used the Johnsons" text as his only reference, it would be almost impossible for him to avoid showing his technique. Their entire approach to composition is inadequate. They identify the "Elements of Composition" as balance, emphasis, focus, correlation, stability, variety, planes and levels or elevations. The first error in their presentation is that what they have discussed are, for the most part, the goals of composition, not the elements. Furthermore, planes and levels are not

${ }^{19}$ Albert and Bertha Johnson, Directing Methods (South Brunswick and New York: A. S. Barnes and Co., 1970), p. 270. ${ }^{20}$ Ibid., p. 278. 
elements of composition, but rather physical contributors to the creation of variety in composition. The definitions of the goals/elements offered by the Johnsons are inadequate and confusing. Emphasis is defined as "one character singled out by isolation, elevation, body position, color, lighting or focus."21 They go on to say, "Focus contributes to emphasis, but is an element all its own." 22 when defining terminology, it is hardly satisfactory to define one new term by using another equally new term, then when defining the second term, to reverse the process. The Johnsons discuss variety, but make no mention of unity. Their discussion of what they call the "elements of composition" is covered in one short paragraph per element. They conclude this section with the statement, "Composed stage pictures should contain most of the elements. The artistry with which a director makes use of the elements will have both an: explicit and implicit effect on the audience."23 Basically, the Johnsons seem to have no grasp of the principles and application of design techniques and their attempt to include this subject in their chapter on "The Magic of Visual Dynamics" could hinder, rather than help, the beginning director trying to use their book.

Play Directing (1971), by Francis Hodge, does not

$$
\begin{aligned}
& 21_{\text {Johnson, p. }} 273 . \\
& 23_{\text {Ibid. . p. } 275 .}
\end{aligned}
$$$$
22 \text { Ibid. }
$$ 
offer the student of directing a firm grounding in design and compositional principles as related to the total stage picture, but not because he presents a confusing discussion of those principles. He choses to discuss the elements of composition only briefly. "It is assumed that the young director can neither absorb [them] or can use [them] at this point." 24 His entire approach to the discussion of composition is unique. He states that "composition is the physical arrangement of actor-character in a ground plan for the purpose of discovering dramatic action and of illustrating it through emphasis and contrast." 25 Later in the chapter he says, "Composition is . . not something arranged for its pictorial value to an audience, but it is a basic device for communicating to actors perceptions about their relationships to other actors."26 This approach removes the design concept from the function of composition. Hodge's definition of composition is

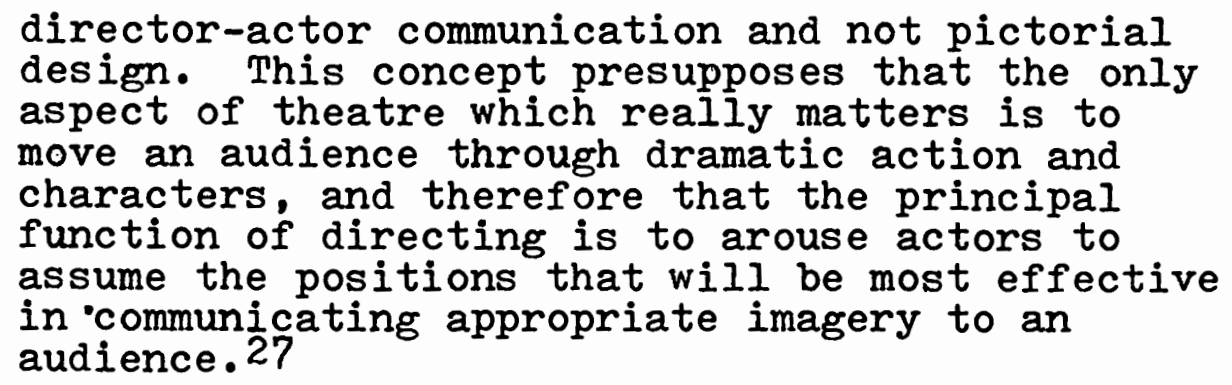

He adds, in a statement aimed directly at the young director,

24 Francis Hodge, Play Directing (Englewood Cliffs, New Jersey: Prentice-Hall, 1971) pp. 115-116.

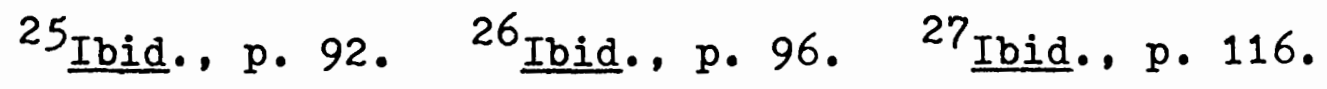


As you grow more experienced, you will develop your own sense of the pictorial, or, like some recent directors, you may regard the pictorial as superficial and relatively non-essential in conveying the meaning of some plays. But you must not aband on the pictorial altogether, for you must recognize that you have failed in your job if a play does not finally communicate to an audience, and the pictorial can definitely help. 28

Therefore, Hodge does not disregard the pictorial, he just de-emphasizes it because he believes that the same results can ultimately be achieved by using his compositional method based on actor-director communication, rather than design-oriented methods. His section on the techniques of composition is divided into major sub-sections entitled, "The Individual Actor" and "The Group--Creating Emphasis." When dealing with the individual actor, he discusses body positions, levels, planes and horizontal locations. When discussing the group, he includes elements of focus, diagonals, triangles, space and mass, repetition and support, climactic compositions and compositions with fumiture. In this section, Hodge presents ideas that are not mentioned in any other directing text. The first is found in the discussion of triangles. He suggests that directors "make a rule for [themselves] not to allow triangles less than two or three planes in depth." 29 He believes this is important because "flat triangles.. . can neither be seen by an audience nor can they convey to actors much sense of rela- 
tionship character." 30 The other suggestion which is unique to Hodge is consciously making furniture on a set into an obstacle course to aid effective composition.

If your ground plan is skillfully devised, you can suggest to actors compositions that will impede them, that is, will keep them from reach-ing one another easily, with the result that they will unknowingly intensify the illustrations of their dramatic actions. 31

Hodge has been discussed at length, even though he does not deal directly with the pictorial or aesthetic aspect of composition. His approach is unique. His ideas are easily understood, but they are difficult to implement. Hodge's contention that the young director cannot absorb or apply the rules of pictorial design is erroneous. As he presents his theories, they are hard to apply. When combined.with a background in the elements of design, the goals of composition and their application to stage direction, the approach might lead to some legitimately innovative directing. As it is, the young director is being asked to apply an abstract theory without knowing the basic facts that support it.

Creative Play Direction, by Robert Cohen and John Harrop, offers no systematic approach to composition in staging, but for reasons different from any of the others. The authors believe that "the old goals of rhythm and usual balance . - as ends in themselves . . are archaic today."

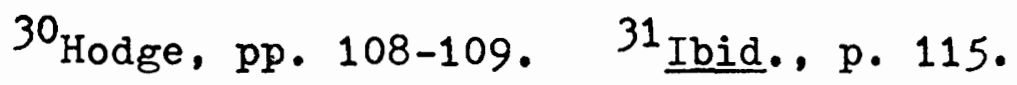


They go on to assert that "the compositional goals of a contemporary director are more than likely guided by his intuitive aesthetic sensibilities." 32 Earlier in the chapter entitled "Blocking," they state,

The director works [the problem being discussed] out by his understanding of the principles of focus and of which ones are strongest in various situations. His synthesis of these principles is not scientific; it comes from his understanding of theatre itself--even from life itself-and from his intuitive and experimental knowledge of which principle will over-ride in each case. 33

This is the second time the reader is told that his "intuition" will guide him toward the correct or most effective decision.

Cohen and Harrop claim that

the dangers of seeing stage composition in terms of art masterpieces is manifold. In the first place, it speaks only to proscenium staging and is generally inapplicable to thrust, arena, or environmental staging. Second, it assumes a single vantage point (the center of the auditorium) from which the stage picture is perfect. 34

They fail to recognize that directing according to their theories alone might be every bit as dangerous. Creative Play Direction, although published in 1974, presents theories expounded during the "Happening" and "Instant Art" period of the middle 1960's. The original creators of "The Happening" were consciously breaking all the rules they had

32 Robert Cohen and John Harrop, Creative Play Direction (Englewood Cliffs, New Jersey: Prentice-Hall, 1974), pp. 134-135.

${ }^{33}$ Ibid., pp. 121-123. ${ }^{34}$ Ibid., pp. $134-135$. 
learned in their formal art school training. The untrained artist looked at the result and saw only the confusion, not the organization or theory behind the confusion. In 1968 . Ann Halprin presented a dance concert in the music auditorium at the University of Oregon. One part of the presentation involved all the audience members. They moved around the room in long lines in seemingly uncontrolled emotional states, ranging from frantic to subdued. The next year, the students at the University of Oregon attempted a similar theatre experience at the Northwest Drama Conference. The results were terrifying. Audience members were climbing on unsecured scaffolding, removing their clothes and frantically trying to experience the "real theatre." The detail the students in charge failed to understand was that Halprin had had her audience/actors in complete control every minute. The participants had been so totally involved they were not consciously aware of the drummer whose ever changing rhythm led them through their gamut of emotions. When their frenzy was nearly out of control, the rhythm slowed and the audience was immediately subdued. There was no drum at the Northwest Drama Conference.

It is not this author's contention that a lack of knowledge of the elements of composition is going to cause the director to lead his cast into frenzied leaps off unsecured scaffolding. The example is only used to illustrate how the inexperienced director can be misled into believing 
that there are shortcuts to creativity.

Cohen and Harrop assume that the inexperienced director has "intuitive judgment." They do not seem to realize that they are able to make judgments based on their intuitive and experimental knowledge of which principle will over-ride in each situation because someone, somewhere, taught them the principle in the first place. In order to create imbalance, the director must first know what makes a composition balanced. In order to create mass confusion, the creative director must know the principles of emphasis. In the theatre, as well as painting, poetry and sculpture, you must know the rules to break the rules. Without the background and understanding of why people react as they do to given stimuli, there are literal as well as figurative dangers in directing.

Creating Theatre, by August Staub, wäs published in 1973. Staub divides the elements of theatre into three groups. They are the visual theatre, kinetic theatre, and the auditory theatre. In chapter seven, "The Visual Theatre," Staub provides the student of directing with a firm grounding in design and compositional principles as related to the total stage picture. Creating Theatre discusses the principles of design and composition in terms of both proscenium and open staging. Staub divides his chapter into easily recognizable sections. The first section discusses the elements of composition, line, form, mass, space, color 
and texture. Next, he discusses the goals of composition. unity, emphasis, balance, rhythm and variety. After defining these elements and goals, he relates them to design, thus combining composition and picturization. Finally, he discusses the relationship between composition, design and dramatic literature. The result is a logically organized, complete discussion of the fundamentals of design as they relate to directing.

Since, at this point, the eight major texts have been introduced and only Staub's has presented a truly systematic examination of the elements and goals of composition, I intend to borrow his organizational scheme for making a detailed examination and comparison of related material in the other texts.

The first element of composition is line. "Line is the basic visual element." 35 Dean and Staub identify the four types of lines. They are vertical, horizontal (straight), diagonal and curved. Dean also includes broken lines. Staub discusses line as it relates to proscenium and arena staging. The relationship between literal and virtual line is examined. Staub and Dean write of line in terms of design elements. The other authors mention line only in terms of focus.

Dean does not define form, the second element of visual composition. He gives, as examples of form, symmet-

35 Staub, Creating Theatre, p. 96. 
rical, irregular, shallow, deep, compact and diffused. 36 Compare this, the only mention of form in the first seven texts, to Staub's definition and discussion.

Lines describe form: form is that which both punctuates and shapes space. In effect, whenever we are speaking of line we are also speaking of the most rudimentary kinds of form. Thus there are straight and curved forms; vertical, horizontal and oblique forms; and various combinations thereof. Another way of classifying form is to divide it into natural and artificial form. A third classification is geometric and organic. 37

Mass, the third element of composition is mentioned by three authors, Dean, Hodge and Staub. Dean defines mass as "a group of figures as opposed to a single individual." 38 Hodge discusses mass in terms of how it relates to space and the emphasis created by mass (actor) surrounded by space. Staub writes, "Line describes form; mass measures form. The measurement is accomplished by three means: weight, density and volume."39 Staub goes on to explain the dramatic significance of various weights, densities and volumes. The basic unit of theatrical mass and form is, of course, the actor.

Staub asserts that the fourth element, space, is the "all-pervading 'element of composition." 40 He says of space: "In its basic state, space is the absence of all form. But when any form is present, space is that element which con-

$$
\begin{array}{ll}
{ }^{36} \text { Dean, p. 168. } & 37_{\text {Staub, p. }} 97 . \quad{ }^{38} \text { Dean, p. } 165 . \\
{ }^{39} \text { Staub, p. 101. } & 40 \text { Staub, p. } 104 .
\end{array}
$$


trasts with form and relates one form to another. "41 Staub discusses positive and negative space, the importance of recognizing available space, and space as it relates to arena and proscenium staging. Despite the importance of the element, space, Hodge is the only other author to mention it.

In Fundamentals of Play Directing, Alexander Dean states,

Color plays a vitally important part in the study of composition in painting, yet in this study of play direction, it is omitted completely. . . Its omission here is due to the fact that in actual stage production it is furnished by the costumes, lighting, and scenery and pot by the director, as such, in his directing. 42

Staub seems to disagree with this reasoning. He includes an extensive section on the technical aspects of color. He explains the four properties of color, hue, value, saturation and temperature. Understanding color enables the director to know how color affects his directing, whether he chooses the colors or not.

Staub is the only author to identify texture as an element or goal of composition. His definition clarifies its importance.

Texture is the surface quality of a visual component. It influences each visual element and is in turn influenced by other visual elements. Texture has three measurements: hard or soft, rough, or smooth, complex or simple. 43

Finally, Staub points out:

$$
{ }^{41} \text { Staub, p. 103. }{ }^{42} \text { Dean, p. 163. }{ }^{43} \text { Staub, p. } 109 .
$$


The director needs to be aware of texture

for two reasons first, because he must adjust

his actors to the texture of the scenery; and second, and more importantly, because he must take advantage of the surface texture provided for the actor through costume and make-up. 44

In this section Staub also describes the various ways visual elements can be combined to change the apparent texture of an object. "In a well executed composition, the elements are so interwoven that it is difficult to distinguish one from the other." 45 If this composition is well executed, and "used to obtain an aesthetically pleasing visual work," 46 it will achieve "the five goals of composition: unity, balance, emphasis, variety and rhythm." 47

This statement clarifies why the other seven texts fail to present a systematic approach to composition. Dean presents the most complete coverage of the goals of the six, but he makes no specific differentiation between goals and elements. Besides this, he discusses the goals before defining the elements. Dean discusses balance and emphasis, omits unity and variety and uses the term sequence rather than rhythm.

Dolman discusses unity, balance, emphasis and rhythm. He adds proportion, harmony and grace and omits variety. The major omission in Dolman's text, however, is his total lack of any discussion concerning the elements of design.

Deitrich discusses emphasis, balance, unity, variety and rhythm, but mentions only the elements of line and space.

$$
{ }^{44} \text { Staub, p. 109. }{ }^{45} \text { Ibid.. p. } 110 .{ }^{46} \text { Ibid. }{ }^{47} \text { Ibid. }
$$


The Johnsons discuss the goals of emphasis, balance and variety, but they call them "elements of composition" and present a confusing and inadequate section on composition. Specific examples of this were delineated above.

In the sections of chapter seven of Creating Theatre that deal with visual unity, emphasis and balance, Staub does not present much new material. Of unity, Staub says, "Anything that appears before the eyes of the audience is either contributing to unity or weakening unity by not making a contribution." 48 Staub claims that "emphasis is a key contributor to compositional unity, "49 an idea reinforced by the fact that emphasis is discussed, at length, by six of the eight chosen authors. In his section on visual balance, Staub discusses not only the physical aspects of balance, but points out how color, space, line, mass and form affect psychological balance.

Rhythm is the fourth goal of composition. The discussion of rhythm provides an excellent example of the confusion that is created when one compares various definitions in a variety of directing texts. Deitrich says, "Coherence means 'to stick together"."50 He defines rhythm as "regular occurance." 51 Dolman defines rhythm as "periodicity or pulsation, or the more or less regular recurrance of emphasis. "52 Compare these definitions to Dean's definition of se-

$$
\begin{aligned}
& { }^{48} \text { Staub, p. 111. } \quad{ }^{49} \text { Ibid. } \quad{ }^{50} \text { Deitrich, p. } 99 . \\
& { }^{51_{\text {Ibid. }}} \text { p. 103. }
\end{aligned}
$$


quence:

The tying together of units on a stage by space. This established space must have a regular recurrance or a repetition of a proportion of that space. Sequence, speaking more broadly, therefore, is space relationship. In effect, it is a regularly recurring accent. It is rhythm in composition, rhythm of distance between figures on stage. 53

Thus, sequence means coherence and rhythm according to Deitrich's terminology. Dolman totally ignores the concept of coherence and discusses only rhythm. To continue the comparison, the Johnsons, in Directing Methods, define correlation as "the element that ties the picture together."54 Correlation, therefore, is the same as coherence, but lacks the rhythm of sequence. Staub's simple explanation of rhythm makes the concept of rhythm in composition quite obvious.

There is no literal rhythm in composition. Virtual or apparent rhythm does, however, exist. Visual rhythm is the apparent or implied flow of compositional parts one into the other in a recognized patterm. 55

When the student director knows the parts, or elements, of composition, it is easy to see how repeating a particular line, form, or texture would create an implied rhythm. The fimal goal of composition is variety. Of this goal Staub says:

Variety may be the all-pervading goal of composition, but it is not the only goal. Visual statements strong in variety but weak in unity,

\footnotetext{
53 Dean, p. $151 . \quad 54$ Johnson, p. 274.

55 Staub, pp. 132-133.
} 
emphasis, rhythm and balance are poor compositions. - . The cardinal rule of variety concerns surprise. Whenever the director feels that the audience knows exactly what to expect of his visual composition, he should surprise them with a logical but unexpected variation. 56

Once again, Staub has identified a concept as "allpervading," this time in terms of the goals of composition and only two other authors have singled it out for discussion. Dean speaks of variety in emphasis and the Johnsons say, "Variety employs such elements as balance and stability, but also makes use of planes and levels... . [It is] also achieved by color, lights and elevation." 57 The inadequacies of the Johnsons' presentation appear again. For all practical purposes, "level" and "elevation" are the same thing. Dolman mentions variety, but only in connection with unity.

The necessity of understanding the elements and goals of composition is explained by Staub in this way:

In the total composition there are no separate elements. Means become goals and goals become means to other goals. So long as a composition is aesthetically satisfying, there is no need to determine how and why it succeeds. An understanding of the compositional process is necessary, however, if one wishes to remedy an unsatisfactory compositional condition or to enhance the impact of. an already strong image. 58

The discussions of the elements and goals of composition found in the eight selected texts have been examined. Staub, alone, has covered each element and goal and his

$$
\begin{aligned}
& 56 \text { Ibid. pp. 133, 137. } 57 \text { Johns on, p. } 274 . \\
& { }^{58} \text { Staub, p. } 137 .
\end{aligned}
$$


systematic approach is obvious. He has defined the elements, identified the goals and has shown how each element affects each goal and how elements and goals affect each other. Staub has pointed out, in a statement much like that of Albright, Halstead and Mitchell, that often the director need not consciously try to achieve the goals, but must judge the final production in terms of those goals. The chart found in the Appendix illustrates which of the elements and goals were discussed in the eight selected texts.

In the next section of chapter seven of Creating Theatre, "Design in the Visual Theatre," Staub incorporates some of the ideas other authors have identified as picturization, i. e., "Visual design--or picturization, as it is often called in the theatre--is the emotional and intellectual meaning of the composition." 59 Alexander Dean is the only other author that devotes a separate chapter to the concept of picturization. That chapter is informative, but it does not clearly relate the elements and goals of composition to the ultimate stage picture. Deitrich combines composition and picturization, which makes a systematic approach to discussing its elements impossible.

Staub's method of presenting design concepts, parallels his presentation of elements and goals of composition. He points out how each of the elements and goals of compo- 
sition affects the goals of visual design. Staub's justification for the detailed examination of the relationships between composition and design can best be summarized by presenting his introduction and conclusion to this section of his chapter.

If the director's task were only composition, his problem would be difficult enough, but the director must design as well as compose. We have defined design as the utilitarian function of an art. In terms of the theatre-visual, design means the joining of the play script with the theatrical picture so that both arts
simultaneously comment on the human experience.

The director is different from such visual artists as the painter and the sculptor. While they design their compositions for meaning, those compositions have no burden to refer to another art. On the other hand, no matter how visually pleasing and meaningful his work may be, the director must always design to support and enrich the work of the dramatic author. 61

The last section of chapter seven clarifies this process of support and enrichment. Staub writes, "The function of the director as a visual designer is to analyze the handling of the conditions of dramatic theme and so arrange his design that the conditions are made clear and rich visually."62 Dramatic forces, the problems of strong and weak, and the problems of dominant and subordinate are dramatic themes Staub relates to visual design. Creating Theatre is the only text that emphasizes the relationship between visual and dramatic composition.

$$
\begin{aligned}
& 60 \text { Ibid., pp. 137-138. }{ }^{61_{\text {Ibid. }}} \text { p. } 154 . \\
& 62_{\text {Ibid. . p. } 155 .}
\end{aligned}
$$


CRITERIA FOR JUDGING ADEQUACY OF

APPROACHES TO COMPOSITION

IN DIRECTING TEXTS

Eight major texts have been examined in depth with regard to their approaches to composition in staging. When the research began on this topic, the basic criteria for an adequate approach to composition was that there must be a correlation between design, in its most basic interpretation, and staging with all its complications. As the research progressed, more definitive criteria developed. Finally, having surveyed the full range of available directing texts and having examined and compared eight of them in depth, this writer has devised the following criteria for judging the adequacy of a directing text's approach to composition and visual design.

First, the author should assume that the student director has no background in the fundamentals of design. He should define, explain and illustrate each of the elements of composition and relate them to theatrical applications. It is a serious handicap to the reader to be asked to make the transfer of a theory from static to kinetic design.

Second, after the author has explained the elements of composition, he should relate these elements to the goals of 
composition. Probably the single most confusing thing in the directing texts examined was the constant confusion between elements and goals. The reader must recognize the lumber and the tools before he can build the house. Third, when discussing the elements and goals of composition, the author should include drawings and photo: graphs that exemplify the concept being considered. The specific way in which a photograph shows the use of the elements should also be explained. For example, in Directing for the Theatre, David Seivers includes a picture of da Vinci's "The Iast Supper" and says, "Note how many different means were used by da Vinci in "The Last Suppex' "63 This is an unsatisfactory approach. When an author asks, "What elements of composition do you see in this picture?" or "How is balance used to express dignity in this photograph?", the reader finds himself looking for the answers in the back of the book. If he knew the answers, he would not need to read the book in the first place.

The fourth requirement for an effective systematic presentation is of design-picturization as separate concepts. This will help the director understand how to use balance, unity, rhythm, emphasis and variety to make the comment the script requires.

Fifth, many authors fail to acknowledge that there

${ }^{63}$ David Seivers, Directing for the Theatre (Dubuque, Iowa: Wm. C. Brown Co., 1965), p. $\frac{105}{10}$ 
will be more on the stage than just the actor or group of actors. The reader must be told how to control all the visual elements of the stage and arrange his compositions so these visual elements re-enforce each other.

I include the following specific suggestions as a supplement to this discussion of evaluative criteria. I do so in the conviction that a failure to include either or both of these features substantially detracts from a directing text's potential value.

A directing text should include color photographs. These are extremely expensive to reproduce and, to keep the price of the text within the reach of the student, authors settle for black and white illustrations. Perhaps methods of cutting expenses in other areas of publication could be found so the advantages of a few colored examples could be utilized. Without color, the reader begins to get the impression that every play ever produced was costumed like "The Ascot Gavotte" in My Fair Lady. A great deal can be learned from a black and white photograph, but occasionally the reader should see how hue, saturation and temperature affect the composition.

Another visual aid that might be used in a directing text is an over-lay. With this device, the reader could add or subtract colors, sets, costumes and properties and discover how each component of the stage picture affects the composition. Since many authors fail to acknowledge that there will be more on the stage than just an actor or group 
of actors, the over-lay system would help the reader visualize methods of controlling all the visual elements of the stage and suggest ways of arranging his compositions so the visual elements re-enforce each other.

If a directing text fulfills these criteria, the reader will have been given a workable presentation of the principles of design and composition as they relate to the total stage picture. 
CHAPTER V

CONCIUSION

Fundamentals of Play Directing was first published in 1941. Until 1973, no author of a directing text made a substantive change in Dean's approach to composition. Dolman stressed compositional goals in terms of the utilitarian function of design, an area in which Dean did not involve himself. Deitrich combined the ideas of Dolman and Dean, but made no major changes in methods of presentation. Directing Methods by Albert and Bertha Johnson attempted to present methods of using composition in staging but confused rather than clarified the problem. Hodge presented an interesting method of dealing with composition in Play Directing. He claimed to avoid the pictorial, yet when analyzed in terms of composition and design, his methods aimed toward the implementation of picturization or design in its elementary form. Hodge did not make a substantive change in Dean's approach to composition; he has avoided the subject almost completely. Creating Theatre was published in 1973. August Staub recognized the contributions made by Dean and Dolman to the practice of teaching directing. He presented his material in a form that indicated that the student of directing had most likely been given no training in composition and design. He assumed that the 
beginning director is familiar with the theatre, but lacks training in the basic techniques. In chapter seven of Creating Theatre, Staub got "back to basics." He explained the elements of composition, related these elements to the goals of composition and finally explained how the elements and goals can be combined by the director to meet the goals of design in the visual theatre. Despite this systematic and detailed presentation, Staub pointed out this is still not enough.

Years of trial and error are necessary for a full understanding of the factors and goals of composition. Even after considerable practical experience, the director will find that each new theatrical situation creates problems of visual relationships that he had never anticipated. Acceptable solutions to such problems are the result of the director's understanding of and experience with the elements and goals of composition. 64

Creating Theatre may not be the best overall directing text available; it is, however, the first text in thirtytwo years to make a substantive change in the approach to composition in staging while still recognizing the need for a knowledge of the aesthetic principles of composition and design.

The ultimate value of this investigation certainly does not lie in the lengthy, often ponderous, summaries of the various directing texts. It does not lie in the conclusions drawn by this writer. Since she is a student of

$$
{ }^{64} \text { Staub, p. } 137
$$


directing herself, as are all directors, her opinion is only one among many. Hopefully, the value of this paper will be judged on the insight it gives the reader about the confusion that exists in the area of teaching the principles of design to directors and other theatre students. No thesis is going to solve the problem. Design cannot be learned by reading a text, no matter how organized it might be. A good text is a beginning, but only that. Students should be encouraged to enroll in design classes; not scene design or costume design, but fundamental design classes. Since a student of theatre will not recognize the need for this information until he is quite advanced in his study, this fundamental class should be available with upperdivision, or even graduate level, credit. The elements and goals of composition must become as much a part of the director's vocabulary as "stage right" and "stage left." The rules must be taught and the principles applied in classroom situations under the direction of one who is knowledgeable in both graphic and dramatic art. Once the student has learned the fundamentals of design and composition, he must, of course, be encouraged to experiment and find his own means of expression. The student should even be allowed to reject the principles or break the rules. What is important to this writer is that the student be given this choice, through knowledge and understanding of the medium in which he must express himself, not be forced into blindly stumbling 
through the process of staging because he has received no instruction in the fundamentals of design. 


\section{ANNOTATED BIBLIOGRAPHY}

Albright, Hardie. Stage Direction in Transition. Encino and Belmont, California: Dickenson Publishing Co., Inc. , 1972.

Albright discusses contemporary forms of theatre and the director's role in their production. Two pages are devoted to composition, but no theories are developed and there is no emphasis on the fundamentals of design.

Albright, H. D., Halstead, W. P. and Mitchell, Lee. Principles of Theatre Art. Boston: Houghton Mifflin Co., 1955.

This text contains a great deal of valuable information about all areas of the theatre. The strength of the text is found in the concise, uncomplicated statements concerning the principles under consideration. The authors do not relate design principles to total stage picture.

Canfield, Curtis. The Craft of Play Directing. New York: Holt, Rinehart and Winston, 1963.

"Aesthetic moves are those used to balance or to unbalance the stage picture or to render the visual effects of a scene more striking by applying the rules of composition; balance, proportion and symmetry to the arrangement of the figures." This is the only statement dealing with composition found in this text. The brevity of the statement, combined with the awareness that Mr. Canfield has listed balance and symmetry as two separate goals of the three goals of composition, would indicate that this selection would not qualify as an authoritative source on the topic of composition in staging.

Cohen, Robert, and Harrop, John. Creative Play Direction. Englewood Cliffs, New Jersey: Prentice Hall Inc., 1974.

This text is based on the theories of theatre development during the late $1960^{\prime} \mathrm{s}$. Audience involvement, directorial intuition and rejection of classical training in composition are its most striking concepts. There is no discussion of the elements of composition and a very limited section dealing with the goals of composition. 
Dean, Alexander, Fundamentals of Play Directing. New York: Holt, Rinehart, and Winston, 1941.

This is the first authoritative text on the fundamentals of directing. Dean includes a highly developed unit on composition in staging. The section concerning methods of emphasis has become the foundation of most discussions of emphasis in most directing texts.

Dean, Alexander, and Carra, Lawrence. Fundamentals of Play Directing. 3rd edition, New Yorks Holt, Rinehart, and Winston, 1974 .

This is exactly the same text as the first and second editions, except that Carra has added a chapter on arena theatre and has updated the photographs.

Dietrich, John. Play Direction. New York: Prentice-Hall, 1953.

Dietrich combines the ideas of Dean and Dolman and contributes a significant amount of additional material. There are no photographs to reinforce discussion of principles.

Dolman, John, Jr. The Art of Play Production. New York, London: Harper and Brothers Publishers, 1946.

Dolman places heavy emphasis on aesthetic values. Although Dolman asserts that, "no stage director can possibly know too much of the principles of design or have his tastes and sensibilities too highly trained," (p. 83), The Art of Play Production has a totally unstructured approach to the application of compositional principles.

Dolman, John, Jr., and Knaub, Richard K. The Art of Play Production. New York, Harper and Row, 1973.

This is the same text as the 1946 edition, but Knaub has added a section on open staging and updated the photographs.

Fernald, John. Sense of Direction. London: Secker and Warburg, 1968.

This text is structured like a conversation. Fernald is mainly concerned with movement and delivery. There is one section on emphasis, but no concentration on stage composition in its other ramifications.

Gassner, John. Producing the Play, rev, ed., New York: Holt Rinehart and Winston, 1953.

A text concerned with the entire scope of play production and the section on play direction written by Worthington Miner, is so condensed that there is no attempt to discuss composition thoroughly. Miner 
seems to be addressing himself to the potential professional, but his ideas are basic and incomplete.

Glenn, Stanley L. A Director Prepares. Encino and Belmont, California: Dickenson Publishing Company, Inc., 1973. Glenn concentrates on specific examples from a particular play when discussing composition and covers only the goals of emphasis.

Gregory, W. A. The Director: A Guide to Modern Theatre Practices. New York: Funk and Wagnalls, 1968. Gregory uses the term "blocking" rather than "composition." He incorporates picturization into his terminology and concentrates on that aspect. There is a heavy reliance on Dean in his section on emphasis. The other goals of composition discussed are focus, lines and shapes, body position, contrast, balance, stability and sequence. Gregory's approach is casual. He does not deal with a structured approach toward the elements of design, nor does he offer a new or unusual approach to composition.

Heffner, Hubert, Sheldon, Samuel and Sellman, Hunton D. Modern Theatre Practice, 4 th ed., New York: AppletonCentury-Crofts, 1959.

Although this text contains a section on composition, it merely defines unity, balance, variety, harmony, and movement in grouping, and defining is not the same as explaining.

Hewitt, Barnard, Foster, J. F. and Sibell, Muriel. Play Production: Theory and Practice. Philadelphiai Lippincott, 1959 .

By the authors' own design, this text is entirely too elementary for a directing student who is advanced enough to be concerned with composition. There is no mention of composition in the text.

Hodge, Francis. Play Directing. Englewood Cliffs, New Jersey: Prentice-Hall, 1971.

Hodge does not discuss the principles of design and composition because it is assumed that the young director can neither absorb or use them at this point. (pp. 115-116)

Johnson, Albert and Johnson, Bertha. Directing Methods. South Brunswick and New York: A. S. Barnes and Co., 1970.

The Johnsons seem to have no grasp of the principles and application of design techniques and their attempt to include this subject in their chapter, "The 
Magic of Visual Dynamics," hinders rather than helps the beginning director.

Lees, C. Lowell. Play Production and Direction. New York: Prentice-Hall, Inc., 1948.

Lists the goals of composition as unity, variety, harmony, contrast, transition, balance, emphasis and subordination, proportion, rhythm and grace. In his attempt to clarify goals by breaking them down into seemingly more elementary terms, Lees succeeds in confusing the issue. He attempts to be casual and conversational, but he fails to explain his ideas clearly enough for effective use by a beginner. $\mathrm{He}$ also fails to mention any of the elements of design.

McMullen, Frank. The Directorial Image: The Play and the Director. New York. The Shoe String Press, 1962. Presents directing from a literary point of view. No systematic approach to composition is presented.

Seivers, W. David. Directing for the Theatre. Dubuque, Iowa: William C. Brown, 1965.

Seivers makes no attempt to teach the art of design in composition. His approach is completely utilitarian, to the extent that he uses an outline format. His section on emphasis has exactly the same material as Alexander Dean, though it is not as complete. Seivers does have an interesting correlation of classic painting and their corresponding compositional principle. The explanation of these correlations is inadequate and would need to be supplemented with knowledgeable lectures. Seivers lists the requirements of effective stage composition. They are unity, balance, emphasis and variety. The composition must also tell a story and be functional. By including the last two requirements, Seivers combines composition and picturization, in an approach similar to that of Deitrich. The text is elementary and there are few original approaches to composition. Its value lies in its outline format. It is a good reference book for the beginning director.

Staub, August $w$. Creating Theatre: The Art of Theatrical Directing. New York: Harper and Row, 1973. Staub discusses the principles of design and composition in terms of both proscenium and open staging. He offers a logically organized complete discussion of the fundamentals of design as they relate to directing. 
Welker, David. Theatrical Direction: The Basic Techniques. Boston: Aliyn and Bacon, Inc., 1971.

Welker places heavy emphasis on detailed preblocking. He presents no emphasis on the art of composition. He is primarily concerned with moving actors for emphasis. The actors are treated as individual entities. The stage and corresponding design elements are not considered. 


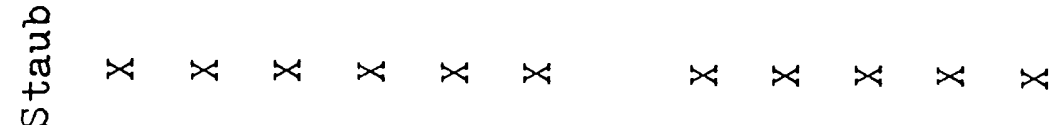

$$
\begin{aligned}
& \text { है }
\end{aligned}
$$

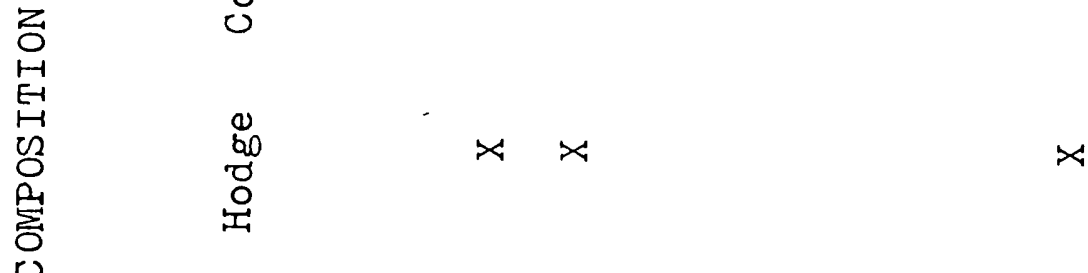

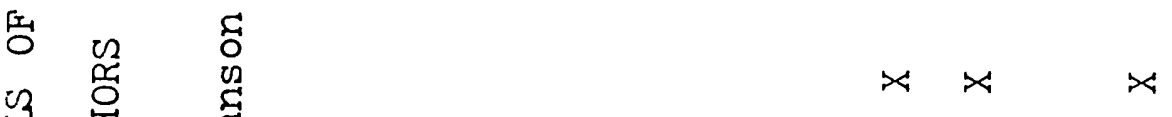

$$
\begin{aligned}
& \text { 凹 } \\
& \text { 星 } \\
& \text { [x] } \\
& \text { 동 덩 } \\
& \text { 桴 } \\
& \text { 年 } x \\
& x \quad x \quad x
\end{aligned}
$$

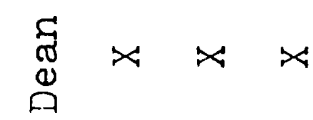

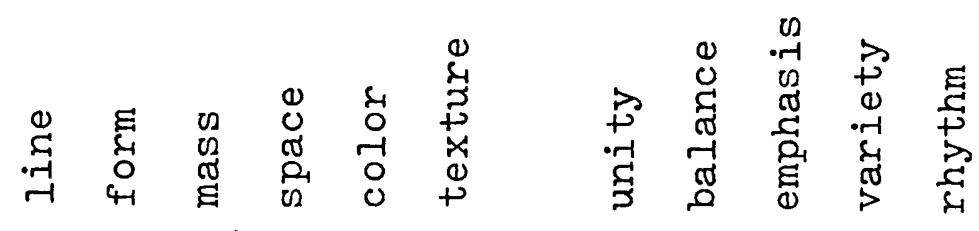

